\title{
Computer Science: The Third Pillar of Medical Education
}

\author{
Frank Lau ${ }^{1}$, Lindsay Katona ${ }^{2}$, Joseph M. Rosen ${ }^{3}$, Charles Everett Koop ${ }^{4}$ \\ ${ }^{1}$ Department of Surgery, Brigham \& Women's Hospital, Boston, USA \\ ${ }^{2}$ Thayer School of Engineering, Dartmouth College, Hanover, USA \\ ${ }^{3}$ Department of Surgery, Dartmouth-Hitchcock Medical Center, Lebanon, USA \\ ${ }^{4}$ Geisel School of Medicine, Dartmouth College, Hanover, USA \\ Email: fhlau@partners.org
}

Received August 31 ${ }^{\text {st }}$ 2012; revised September 28 ${ }^{\text {th }}$, 2012; accepted October $12^{\text {th }}, 2012$

\begin{abstract}
In 2001, the Institute of Medicine (IOM) and the National Academy of Sciences (NAS) attributed substantial problems in the quality of American medicine to four domains: growing complexity of science and technology; the increase in chronic conditions; a poorly organized delivery system; and constraints on exploiting the revolution in information technology (IT). Although all of these domains have been improved by IT systems within the last decade, the U.S. health care systems has been slow to adopt these developments. We propose one way to combat such quality problems by incorporating a medicine-specific computer science (CS) curriculum as the third of Abraham Flexner's pillars of medical education.
\end{abstract}

Keywords: Information Technology; Computer Science; Medical Education

\section{Introduction}

Meanwhile the requirements of medical education have enormously increased. The fundamental sciences upon which medicine depends have been greatly extended... The education of the medical practitioner under these changed conditions makes entirely different demands in respect to both preliminary and professional training.

$$
\text { —Abraham Flexner (1910) }
$$

Flexner's first pillar of medical education was clinical experience. His report catalyzed rapid, systemic change, allowing experimental science to become the second pillar. The subsequent fusion of research and teaching - the academic medical school-remains intact today.

Today, medicine is slow to incorporate two forces that have altered nearly every aspect of our lives: computer science (CS) and information technologies (IT). The result is an inability to properly address many of the mounting challenges and expectations of modern medicine. For example, electronic medical records (EMRs) are the modern standard, but Jha and colleagues (2011) found only 15\% of hospitals used them as of 2010.

Many factors contribute to these delays. But fundamentally, very few physicians have formal CS training. We are therefore hamstrung in implementing IT solutions. We are unqualified to participate in designing and developing transformative applications. We are poorly equipped to apply the intellectual rigor of $\mathrm{CS}$ in research and clinical problem solving.

To overcome this problem, one solution is to incorporate a formal, medicine-specific CS curriculum as the third pillar of medical education.

On the surface, our proposal may seem heavy-handed. After all, an entire industry of IT professionals exists. And, the act of programming might seem unrelated to patient care. But CS and medicine revolve around the same core processes: the gathering, storage, and interpretation of data. Moreover, clinical and re- search data are increasingly digitized. By giving physicians the intellectual tools to deeply shape and understand healthcare IT, medicine-specific CS education will be a boon to our profession. A parallel shift has started in journalism, with Columbia University announcing a dual-degree program in journalism and computer science (2010).

History makes a powerful case for incorporating CS into medical education. Four paradigms have governed the progress of science (Bell, Hey, \& Szalay, 2009). The first paradigm of empirical science relied on observations and empirical data. Next, we developed the second paradigm of theoretical science (e.g. Newton's laws). Flexner's report led American medical education to adopt these two paradigms, ultimately yielding our present-day models of physiology and disease.

With the advent of computing, the third paradigm of simulation (e.g. weather modeling) became possible. Today, in response to the data explosion of the past decade, a fourth paradigm of technologies for data-intensive science is rapidly emerging. These two paradigms fulfill clear needs within medicine. For example, physiology simulations offer the promise of intervention or drug testing without costly, time-intensive, and potentially dangerous clinical trials (Eddy \& Schlessinger, 2003). Similarly, the mountains of digitized, clinical data coming out of patient care settings make fourth paradigm tools a necessity. By building the third pillar of medical education around these third and fourth paradigms of science, we will generate benefits in the key realms of Patient Care, Education, Service, Research, and Finance.

\section{Patient Care Benefits}

A CS-proficient physician workforce would drive the adoption of healthcare IT. Patient care would directly benefit. In 2001's "Crossing the Quality Chasm: A New Health System for the 21st Century," the Institute of Medicine (IOM) and the National Academy of Sciences (NAS) found "abundant evidence that serious and extensive quality problems exist throughout 
American medicine resulting in harm to many Americans." This report highlighted 4 contributory domains: "growing complexity of science and technology, the increase in chronic conditions, a poorly organized delivery system, and constraints on exploiting the revolution in information technology."

All of these domains have been improved by information technology (IT) systems (Dexter, Perkins, Maharry, Jones, \& McDonald, 2004; Kucher et al., 2005; Litzelman, Dittus, Miller, \& Tierney, 1993). These systems have been available for years. Examples include EMRs, computerized order entry systems, and electronic prescription systems. But adoption remains slow. Barriers to adoption include initial cost, physician time requirements, difficulties with technology, and inadequate support (Miller \& Sim, 2004; Pizzi, Suh, Barone, \& Nash, 2005). Tellingly, several of these barriers stem from a lack of CS/IT literacy. Physicians well-versed in computers would require less training, experience less initial difficulty, and would require less IT support.

Eleven years have passed since the IOM/NAS's report without significant progress in applying IT to improve patient care. The federal government is preparing to force the implementation of basic healthcare IT systems. Rather than be pushed along, we should lead these efforts.

\section{Educational Benefits}

As a pillar of medical education, CS benefits medical students and physicians in two discrete domains: critical thinking and lifelong learning. The optimal time for this training is during the preclinical years of medical school. This way ensures that the CS courses are relevant to physician careers. This would also set the stage for applying CS to lifelong learning, a crucial task for physicians.

With regards to critical thinking, the learning process behind programming is uniquely well-suited to medicine: good programming has many parallels to good surgery. For example, programs must be carefully designed in advance. Contingencies must be planned for, vulnerabilities identified, and checks implemented. When things go wrong and the program needs debugging, the programmer must proceed step-wise through the program, considering all possible conflicts, until the problem is identified. Good surgeons use similar processes to plan, execute, and problem-solve their surgeries. Unlike surgery, in CS these processes are easily reproducible and do not require a patient. In this sense, CS offers the opportunity to sharpen critical thinking at an accelerated rate and in a safe setting.

By learning how to program, medical students will enhance their lifelong learning because they can develop applications specifically for physician learning needs. This should be part of their CS training. For example, a medical student could write an application to summarize key findings from the 80,000 clinical trials that are conducted annually (ACRO, 2010). Such a program would yield lifelong returns by keeping our knowledge base updated.

Alternatively, a student could create a program to address the problem of knowledge attrition. We know that physicians forget a tremendous amount of knowledge, even when that knowledge is clinically relevant. For example, Ali and colleagues (1996) found in a study involving practicing trauma physicians that, 6 months after successfully completing an Advanced Trauma Life Support course, 50\% failed a repeat test. A knowledge management program could track our rate of knowl- edge attrition and prompt us to review critical material before we forget it.

Medical students could drive the development of digital simulators. In the past 7 years, non-medical simulation has advanced tremendously. Powerful graphics cards allow for highly realistic situational gaming and mobile gaming is everywhere. Despite these gains, digital simulation plays a small role in medical education.

We propose that medical schools develop simulator platforms specifically for medical education. These platforms should focus on effective learning (Issenberg, McGaghie, Petrusa, Lee Gordon, \& Scalese, 2005). They should allow clinical scenarios to be presented with high-fidelity. Students should be required to program their own simulations using these platforms. Analogous to tradition of student presentations, the authoring of simulations will help students delve into clinical entities. However, these simulations could be shared with other students, yielding a comprehensive educational library.

\section{Service Benefits}

Service, or the contract between the patient and the physician, is the very heart of medicine. But a service gap now exists (Grumbach, 1999; Moore \& Showstack, 2003). IT solutions have been shown to improve this gap, but most physicians remain reluctant to implement them. Because computing proficiency correlates positively with healthcare IT adoption, CStrained physicians are better able to close the service gap (Kaushal, Bates, \& Jenter, 2009).

For example, the American Medical Association published guidelines for clinical emails in 2001. As of 2006, Brooks and Menachemi found only $16.6 \%$ of Florida physicians used email to communicate with their patients. Security and legal concerns are oft-cited barriers to the adoption of email communications. Security concerns are no greater than those faced by the banking industry, which has safely launched online and mobile banking platforms. Similarly, no lawsuits have ever been brought for medical advice given via email.

Newer technologies such as text messaging have been shown to improve patient compliance in the management of type 1 diabetes and liver transplants (Franklin, Waller, Pagliari, \& Greene, 2006; Miloh et al., 2009). Videoconferencing and telemedicine also promise to restore the doctor-patient relationship while lowering overall costs. But until physicians attain a high level of comfort with information technologies, we expect a significant lag in using these tools to renew the patient-doctor relationship.

\section{Research \& Innovation Benefits}

A CS-proficient physician workforce will reap benefits in research and innovation. The recent explosion of data from every sector of medicine is currently an untapped gold mine. As clinical records become digitized, this volume of data will only grow. From bioinformatics to clinical research, physicians who possess the intellectual framework for manipulating and understanding this data will generate novel insights. For example, when routine text-mining methods were applied to published abstracts, three novel rheumatoid arthritis risk loci were identified (Raychaudhuri et al., 2009).

Physicians who understand CS will drive healthcare IT innovation. For example, we currently lack national standards for 
EMR interoperability. Physicians should lead the development of these standards, but we cannot do so without CS fluency. Medical students should drive the development of learning platforms. Motivated and trained physicians will finally push medicine into the third and fourth paradigms of computer science, perhaps perfecting applications like the Archimedes model, a full-scale simulation model of human physiology, diseases, behaviors, interventions, and healthcare systems (Eddy \& Schlessinger, 2003).

\section{Finance Benefits}

In 2009, healthcare spending comprised $17.3 \%$ of the gross domestic product (Truffer et al., 2010). This is projected to grow to one third of national income by mid-century (Hagist \& Kotlikoff, 2006). A cornerstone of current governmental efforts to combat the rising cost is EMRs. Girosi (2005) projects $\$ 80$ billion per year of cost savings if effective EMRs are implemented nationally. Given the current shortage of specialists capable of supporting healthcare IT, the best strategy for driving this implementation is to broadly increase the number of CS-proficient physicians.

This physician workforce would also allow for the implementation of additional, technologically sophisticated healthcare IT solutions. Examples include Cybercare, a proposed distributed network-based healthcare system that shifts the focus back to preventive care (Koop et al., 2008). Other technologies such as telemedicine, remote monitoring, and robotics for telesurgery/telemedicine can increase patient healthfulness, access to care, and systemic efficiency.

\section{Building the Third Pillar}

Integrating CS into the medical school curriculum is a massive undertaking. But it is no larger than the integration of experimental science that took place a century ago and the benefits make it equally worthwhile. The proper development of this curriculum should be undertaken by a national committee. Each medical school should be evaluated to identify what is working, and more importantly, what is missing. Schools that do not uphold minimum standards need to implement a plan for getting up to speed. We believe medical students should, at a minimum, learn one scripting language, develop one databasedriven application, and create an extension for another program. To maximize the medical relevance, this training must take place in medical school.

The proposed process would capitalize on two theories of education, namely social learning theory and constructivism. Social learning theory would be most valuable during the students' introduction to a scripting language. Instructors, perhaps in a virtual form, could model programming techniques while demonstrating their applications to medicine (Ormrod, 1999). In accordance with constructivism, the students will build confidence through mastery of a scripting language. When challenged to develop a database-driven application, they would cement their role as active participants at the intersection of CS and medicine. By creating an extension for another program, they would be responsible for refining their skills in a way that they deem relevant. This merger of theories would ideally be accomplished within learning and digital simulation platforms (Sharma, Xiem Hsieh, Hsieh, \& Yoo, 2008). Considering the potential to blend learning theories with emerging technology, the construction of this third pillar of medicine presents a wor- thy yet manageable endeavor.

\section{REFERENCES}

ACRO (2010). The CRO market. http://www.acrohealth.org/61

Ali, J., Cohen R., Adam, R., Gana, T. J., Pierre, I., Ali, E., Bedaysie, H. et al. (1996). Attrition of cognitive and trauma management skills after the Advanced Trauma Life Support (ATLS) course. Journal of Trauma and Acute Care Surgery,40, 860-866. doi:10.1097/00005373-199606000-00002

American Medical Association (2001). Guidelines for physician-patient electronic communications.

http://www.ama-assn.org/ama/pub/about-ama/our-people/member-gr oups-sections/young-physicians-section/advocacy-resources/guidelin es-physician-patient-electronic-communications.shtml

Committee on Quality of Health Care in America (2001). Crossing the quality chasm: A new health system for the 21st century. Washington, DC: National Academies Press.

Bell, G., Hey, T., \& Szalay, A. (2009). Computer science. Beyond the data deluge. Science, 323, 1297-1298. doi:10.1126/science.1170411

Brooks, R. G., \& Menachemi, N. (2006). Physicians' use of email with patients: Factors influencing electronic communication and adherence to best practices. Journal of Medical Internet Research, 8, e2. doi:10.2196/jmir.8.1.e2

Columbia University (2010). Columbia University announces new dualdegree Master's program in journalism and computer science. http://news.columbia.edu/oncampus/1980.

Dexter, P. R., Perkins, S. M., Maharry, K. S., Jones, K., \& McDonald, C. J. (2004). Inpatient computer-based standing orders vs physician reminders to increase influenza and pneumococcal vaccination rates: A randomized trial. Journal of the American Medical Association, 292, 2366-2371. doi:10.1001/jama.292.19.2366

Eddy, D. M., \& Schlessinger, L. (2003). Validation of the Archimedes diabetes model. Diabetes Care, 26, 3102-3110. doi:10.2337/diacare.26.11.3102

Flexner, A. (1910). Medical education in the United States and Canada. Boston, MA: The Merrymount Press.

Franklin, V. L., Waller, A., Pagliari, C., \& Greene, S. A. (2006). A randomized controlled trial of Sweet Talk, a text-messaging system to support young people with diabetes. Diabetic Medicine, 23, 1332-1338. doi:10.1111/j.1464-5491.2006.01989.x

Girosi, F. (2005). Extrapolating evidence of health information technology savings and costs. Santa Monica, CA: RAND Corporation.

Grumbach, K. (1999). Primary care in the United States-The best of times, the worst of times. New England Journal of Medicine, 341, 2008-2010. doi:10.1056/NEJM199912233412611

Hagist, C., \& Kotlikoff, L. J. (2006). Health care spending: What the future will look like. Dallas, TX: National Center for Policy Analysis, Boston University, National Bureau of Economic Research.

Issenberg, S. B., McGaghie, W. C., Petrusa, E. R., Lee, G. D., \& Scalese, R. J. (2005). Features and uses of high-fidelity medical simulations that lead to effective learning: A BEME systematic review. Medical Teacher, 27, 10-28. doi:10.1080/01421590500046924

Jha, A. K., Burke, M. F., DesRoches, C. M., Joshi, M. S., Kralovec, P. D., Campbell, E. G., \& Buntin, M. B. (2011). Progress toward meaningful use: Hospitals' adoption of electronic health records. American Journal of Managing Care, 17, 117-124.

Kaushal, R., Bates, D. W., Jenter, C. A., Mills, S. A., Volk, L. A., Burdick, E. et al. (2009). Imminent adopters of electronic health records in ambulatory care. Informatics in Primary Care, 17, 7-15.

Koop, C. E., Mosher, R., Kun, L., Geiling, J., Grigg, E., Long, S. et al. (2008). Future delivery of health care: Cybercare. IEEE Engineering in Medicine and Biology Magazine, 27, 29-38. doi:10.1109/MEMB.2008.929888

Kucher, N., Koo, S., Quiroz, R., Cooper, J. M., Paterno, M. D., Soukonnikov, B., \& Goldhaber, S. Z. (2005). Electronic alerts to prevent venous thromboembolism among hospitalized patients. New England Journal of Medicine, 352, 969-977. doi:10.1056/NEJMoa041533

Litzelman, D. K., Dittus, R. S., Miller, M. E., \& Tierney, W. M. (1993). Requiring physicians to respond to computerized reminders improves 
their compliance with preventive care protocols. Journal of General Internal Medicine, 8, 311-317. doi:10.1007/BF02600144

Miller, R. H., \& Sim, I. (2004). Physicians' use of electronic medical records: Barriers and solutions. Health Affairs (Millwood), 23, 116126. doi:10.1377/hlthaff.23.2.116

Miloh, T., Annunziato, R., Arnon, R., Warshaw, J., Parkar, S., Suchy, F. et al. (2009). Improved adherence and outcomes for pediatric liver transplant recipients by using text messaging. Pediatrics, 124, e844e850. doi:10.1542/peds.2009-0415

Moore, G., \& Showstack, J. (2003). Primary care medicine in crisis: Toward reconstruction and renewal. Annals of Internal Medicine, 138, 244-247.

Ormrod, J. E. (1999). Human learning (3rd ed.). Upper Saddle River, NJ: Merrill Prentice Hall.

Pizzi, L. T., Suh, D., Barone, J., \& Nash, D. B. (2005). Factors related to physicians' adoption of electronic prescribing: Results from a na- tional survey. American Journal of Medical Quality, 20, 22-32. doi:10.1177/1062860604273775

Raychaudhuri, S., Thomson, B. P., Remmers, E. F., Eyre, S., Hinks, A., Guiducci, C. et al. (2009). Genetic variants at CD28, PRDM1 and $\mathrm{CD} 2 / \mathrm{CD} 58$ are associated with rheumatoid arthritis risk. Nature $\mathrm{Ge}$ netics, 41, 1313-1318. doi:10.1038/ng.479

Sharma, P., Xie, Y., Hseih, P., Hseih, W., \& Yoo, S. (2008). Student learning outcomes in technology-enhanced constructivist learning environments: What does research show? In M. Orey, V. J. McClendon, \& R. M. Branch (Eds.), Educational media and technology yearbook 2008 (pp. 77-90). Westwood, CT: Greenwood Publishing Group, Inc. Truffer, C. J., Keehan, S., Smith, S., Cylus, J., Sisko, A., Poisal, J. A. et al. (2010). Health spending projections through 2019: The recession's impact continues. Health Affairs (Millwood), 29, 522-529. doi:10.1377/hlthaff.2009.1074 